\title{
Research on Autonomous Learning in English in Higher Education
}

\author{
Xiu Zeng \\ Foreign Language Department, NanChang Normal University \\ Postcode: 330029; 2267395464@qq.com
}

\author{
Keywords: Analysis; Learner autonomy; Contributing factors
}

\begin{abstract}
Learner autonomy has caught much attention in the field of language education and research in the past decades, especially in relation to lifelong learning skills. It has transformed old practices in the language teaching and learning and become a central theme in language instruction. Autonomy facilitates learners to apply the knowledge acquired in a given context to different situations. This paper mainly focuses on a brief analysis of self-study in English learning in higher education, and discusses the contributing factors in self-study and the roles they play in learner autonomy.
\end{abstract}

\section{Introduction}

There can be no doubt that English is one of the world's most widely used languages and also one of the few "working" languages of the United Nations. In China, more and more people pay much attention to the ways of English learning. School education is a very important means to English learning; yet, no one can learn everything from school because of the limit of the time, money, energy or some other personal reasons. Therefore, learners' autonomy, self-study or self-learning, is introduced as a skill of getting knowledge and information by students themselves.

The above suggested self-learning can promote the approach where students study independently choosing from among different resources that are available. The advantage of this style of learning is that students, especially foreign language students, learn better if they have a say in how they learn. Further, learner autonomy and self-directed learning can greatly change the way the traditional teaching is done. Nowadays, in many college English classes, teaching remains largely teacher-dominated, teachers give lectures just as a king issues an order for subjects to follow while students just sit there waiting to be taught. There is not much exchange of ideas during class time between teachers and students. Such a teaching may possibly result in either less school attendance or more absence of mind. Therefore changes are necessary and inevitable; learner autonomy may be a cure for it.

This paper mainly focuses on a brief analysis of self-study in English learning in higher education, and discusses the contributing factors in self-study and the roles they play in learner autonomy.

\section{The Definition of Learner Autonomy}

The concept of learner autonomy has been introduced into foreign language teaching over twenty years. Nowadays, autonomy has been widely accepted as an educational goal and few teachers will disagree with the importance of helping language learners become more autonomous as learners. But as to what learner autonomy really is, various interpretations have been proposed by different researches and scholars in different contexts.

Holec defines learner autonomy as "the ability to take charge of one's own learning"[1] . Many researchers agree with Holec that learner autonomy is ability or a capacity. For example, Little sees learner autonomy as a capacity for "detachment, critical reflection, decision-making and independent action" [2]. Nunan also believes that this ability is extraordinary important--the learners who are able to fix their own aims and produce chances for learning are autonomous learners [3]. Littlewood talks about learner autonomy as "the ability to use the knowledge one has learned without the help of the teacher". One of the widely accepted of learner autonomy is put 
forward by Benson who defines it as "the capacity to take control of one's own learning". Dickinson [4] sees autonomy very much as an attitude to language learning. In his opinion, autonomous learners are ready to take responsibility for their own learning and show their willingness by setting their own goals, selecting their materials, deciding on their own methods, place time and pace for study, monitoring their study and making proper evaluation.

These definitions deal with the concept of learner autonomy and go some way towards clarifying the characteristics of autonomous language learners. Researchers hold different views on degrees of autonomy and point out that learners' potential for achieving different degrees depends on factors like their personality, their goals, their attitudes, learning strategies, institutional philosophy and cultural context.

\section{The Contributing Factors in Learner Autonomy}

The concern of the present study has so far been with outlining the general characteristics of autonomy. Through research, it is recognized that autonomous learning is achieved on certain conditions: motivation, attitudes, learning strategies, cognitive styles and evaluation, etc. Therefore, it is very necessary for teachers to pay much attention to these factors for the aim of developing students' autonomy in English learning.

\section{Motivation}

Scholars seem to agree that one of the key factors that influences the rate and success of the second or foreign language learning is motivation. It has several effects on students' learning and behavior. It directs behavior toward particular goals. It leads to increased effort and energy that learners expend in activities directly related to their needs and goals. It provides the primary impetus to initiate learning the foreign language and later the driving force to sustain the long and often tedious learning process. A number of reviews and discussions provide evidence that motivation and learner autonomy go hand in hand. Therefore, no matter from which angle we consider the relationship, we must recognize the important role that motivation plays in learner autonomy.

In order for English teachers to motivate students, much is required for teachers to take, say, "positive self-concept, high self-esteem, positive attitude, clear understand ing of the goals for language learning, continuous active participation in the language process, the relevance of conductive environment that could contribute to the success of language learning", according to Hussin, Maarof and D'Cruz. They strongly believe in three specific elements to build motivation towards language-learning: self- confidence, experiencing success and satisfaction, and good teacher-learner relationships as well as relationships between learners.

To be more specific, we can say that it is a teacher's duty to encourage learners in case of failure and assure them of possible reward of constant efforts, and to praise them in case of success for further progress. Also the teacher and the learner can work towards autonomy by creating a friendly atmosphere characterized by "low threat, unconditional positive regard, honest and open feedback, respect for the ideas and opinions of others, approval of self-improvement as a goal, collaboration rather than competition", (Candy)[5].

Therefore, all the three factors are believed to be correlated to each other in the process of motivation development.

\section{Beliefs and Attitudes}

The term "attitude" has been defined in many ways. Common to psychological theories on attitudes is the notion that attitudes actually have three components: affect, cognition, and behavior. Affect concerns feelings, moods, and emotions toward the attitudinal object, for example, some learners may agree with the idea that they should take more responsibility for their learning, while others may prefer to depend on the teacher. Cognition refers to what a person knows about the attitudinal object. In language learning, it refers to "attitudes learners hold about their role in the learning 
process and their capability as learners". And the third attitudinal component, behavior, has to do with intentions or actions related to the attitudinal object. Learners who hold positive attitudes toward learner autonomy may be more likely to take the responsibility than those who hold negative attitudes. it is manifest that changing some negative beliefs and attitudes is bound to facilitate learning. Attitude change is assumed to be brought about through exposure to a persuasive communication between the teacher and the learners. These affective reactive reactions, cognitions, and behaviors comprise the overall attitude toward language and culture.

Accepting new ways of language learning requires a fundamental and drastic change in perception from both learners and teachers about how languages are learned. Learners who have undergone a systematic education process develop certain beliefs about how learning should take place. Everyone is, to some extent, conditioned by the educational environment they experience. In language learning, beliefs and attitudes are shaped not only by the educational environment but also by family and social values. These influences on approaches to learning a language may either contribute to or impede the development of their potential for autonomy. Positive attitude towards learner autonomy can be expected to enhance learning and negative attitudes can only be expected to impede learning. So for teachers, identifying learners' attitudes and modifying negative attitudes should be the important step in autonomous learning.

\section{Learning Strategy}

Language learning strategies are generally defined as specific actions, behaviors, steps or techniques that learners use to make language learning more successful, self-directed and enjoyable(Oxford) [6].

Learning strategies are the conscious thoughts and behaviors used by learners with the explicit goal of improving their knowledge and understanding of a target language [7]. Learning strategies are the mental and communicative procedures or techniques learners use to learn and use language effectively [3].

In spite of uncertainties in these definitions, anyway, all the definitions recognize that they are used efforts to learn about the target language. Hence, learning strategies consist of mental and physical behaviors that a learner deploys to make their learning more effective in the process of language acquisition.

All learners have certain preferred learning strategies and employ them more or less consciously. Learning strategy is firmly believed to be the key to promoting learner autonomy and when students are inhibited to use their preferred strategy, it is impossible for them to learn English efficiently. We can find that learning autonomy is the most important individual factor relating to learner autonomy and we can find that helping students understand the importance of strategies and use some strategies suitable for them is an effective way to enhance their learner autonomy.

According to Wenden[8], a good way of helping students become aware of their learning strategy is to assign a task and have them report what they are thinking while performing it. This self-report is called introspective, as learners are asked to introspect on their learning. Introspective reports are assumed to provide information on the strategies learners are using at the time of the report; it is a means of raising awareness of learners' strategies and the need for constant evaluation of techniques, goals and outcomes. As Wenden observes [8] "without awareness learners will remain trapped in their old patterns of beliefs and behaviors and never be fully autonomous".

J.LM.Trim points out "teachers of modern languages have the responsibility to equip learners with the learning strategies they need in order to continue language learning as required by the challenge of adult life in a rapidly changing world". Therefore, to achieve this goal, teachers themselves have to learn what specific learning strategy should be employed in specific case, regularly check how students are going ahead with learning strategies, and then assist them in modifying and reconstructing their cognitive knowledge if a misinterpreted strategy is obstructing their learning and their potential for autonomy. 


\section{Assessment and Evaluation}

Assessment need to become an integral part of self-learning work even though many of them may be very small scale and not credit-earning in an institutional sense. Holec refers to self-assessment as 'an integral part of the learning'. This is echoed by Tudor who sees it as 'central to the active and reflective involvement of learners' and by Thomson who shows that self-assessment procedures "involve learners to a much higher degree in learning than any prescribed learning". Holec also showed that "all learners practise self-evaluation of one kind or another".

The assessment of self-learning is necessary in that it serves purposes for learners. Assessments are essential to learners as a way of evaluating the effectiveness of self-learning as a personal tool. Autonomy is a new approach to studying for many learners and lacks the traditional system of feedback on achievement inherent in teacher-led education [9]. Assessments, even on a small scale, can provide learners with feedback on how they are doing and may lead them to reassess their approach or to motivate them to further study. Assessments can also be seen as useful language practice and practice for taking examinations.

As in learner-centered curriculum, both teachers and learners need to be involved in evaluation. Any element in the curriculum process may be evaluated, the concepts of validity and reliability are crucial to assessment. Teachers are expected to decide when and how the evaluation should be conducted. Evaluation, as a process in its own right, rather than as a final product of the evaluation process, may be done at any time.

\section{Conclusion}

Learner autonomy is "an important and efficient approach to enhance English teaching in China "(Rongping Cao) [10] and "an economical solution to the problem of insufficient English teachers in China and as a remedy for lack of concern for individual needs" (Xiaoling Wang)[11]. So it is not hard for us to to expect the contribution it makes to the personal growth of learners and the development of language learning. Autonomy affords maximum possible influence to the learners and encourages and needs peer support and cooperation. With the focus moving from teaching to learning, learners becomes the center of language teaching.

\section{References}

[1] Holec, H.: Autonomy and Foreign Language Learning (Pergamon Press, Oxford 1981) .

[2] Little, D.1990. Autonomy in Language Learning: some Theoretical and Practical Considerations. London: CILT.

[3] Nunan, D.1997. Designing and Adapting Materials to Encourage Learner Autono my. London Longman.

[4] Dickinson, L.1987. Self-Instruction in Language Learning. Cambridge: Cambridge University Press.

[5] Candy, 1991.Self-Direction for Lifelong Learning. California: Jossey-Bass.

[6] Oxford, R.L.1990. Language Learning Strategies: What every teacher should know. Boston.

[7] Cohen, A.D, Strategies in Learning and Using a Second Language. London: Longman, 1998.

[8] Wenden, A. 1998. Learner Strategies for Learner Autonomy. Great Britain: Prentice Hall.

[9] David,G. 2002. Establishing Self-Access. Cambridge: Cambridge University Press.

[10]Rongping Cao. 2003. Respecting Individual Differences and Promoting Learner Autonomy in China's Foreign Language Teaching. Teaching English in China.

[11]Xiaoling Wang. 2002. On Autonomy. Some Theoretical and Pedagogical Consideration for Chinese EFL Context. Teaching English in China. 